\title{
XXIII. Analytical essay on asparagus
}

\section{Robiquet junior}

To cite this article: M. Robiquet junior (1806) XXIII. Analytical essay on asparagus, Philosophical Magazine Series 1, 26:102, 115-120, DOI: 10.1080/14786440608563647

To link to this article: http://dx.doi.org/10.1080/14786440608563647

$$
\text { 曲 Published online: } 18 \text { May } 2009 .
$$

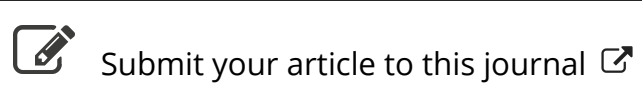

\footnotetext{
Џll Article views: 2
}

Q View related articles $\asymp$ 
the manner in which it is scattered amongst another substance, and blended with it, have not allowed of more qualities being determined, but I apprehend these to be sufficient to establish its nature.

This native minium seems to be produced by the decay of a galena, which I suspect to be itself a secondary production from the metallization of white carbonate of lead by hepatic gas. This is particularly evident in a specimen of this ore, which I mean to send to Mr. Greville as soon as I can find an opportunity. In one part of it there is a cluster of large crystals. Having broken one of these, it proved to be converted into minium to a considerable thickness, while its centre is still galena.

I am, 8xc.

Cassel in Hesse,

March 2, 1806.

JAMES SMITHSON.

XXIII. Analytical Essay on Asparagus. By M. RoвIQUET junior, Apothecary at Vale de Grace.

[Concluded from p. 38.]

Arter what has been stated, we cannot conclude, with M. Antoine, that the acid obtained from asparagus by the process pointed out is malic acid. The difference is very remarkable. The latter forms with barytes, strontian, and. lime, salts a little soluble; while those of the former are very insoluble. We may be convinced of this by taking equal proportions of these two acids, supposed to be of the same degree of concentration, and afterwards diluted with a great quantity of water. If we pour into these two liquors, drop by drop, a solution of lime for example, a precipitate show's itself with the acid obtained from asparagus; but the malic acid does not give any trace of one, provided always that the liquors be sufficiently diluted. The same thing takes place with barytes or strontian. A character still more marked is that of decomposing the sulphate of iron, the acetates of iron and of copper, which the malic acid does not. Besides, as I have formerly recalled to the reader's recollection, the malate of lead is soluble in vinegar; but 
the precipitate formed by the other acid in the acetate of lead refuses altogether to dissolve itself therein, whatever quantity be employed. The malic acid, besides, does not decompose earthy acctates.

The malate of magnesia is so very deliquescent that it has been proposed by M. Chenevix as the means of separating alumen from magnesia, by treating those two earths with malic acid and dissolving them it: alcohol; and since the acid of asparagus, when saturated with an alkali, precipitates abundantly the muriate of magnesia, if, as I have said, the solutions are concentrated, we may infer that this salt is not soluble in spirit of wine.

It is equally impossible to confound this acid with rinegar, since it decomposes almost all the earthy and metallic acetates.

Its property of not crystallizing prevented me from comparing it with other vegetable acids, and I could not, with any bettcr appearance of probability, regard it as a mineral acid, since when submitted to the action of heat it became charred. I was therefore naturally led to believe it a new acid: but having communicated my experiments to M. Vauquelin, he advised me to examine carefully its combinations with earthy bases, and from this examination resulted, as we shall see, the discovery of its nature.

I precipitated it by lime water, and after filtering and washing it well, I calcined it in a silser crucible. On the first action of the heat this salt blackened, and gave out at the same time a slight anmoniacal odour. I continued this process until there no longer remained a trace of carbonaceous matter: the residue was insipid, and insoluble in water. I boiled it with distilled vinegar. I filtered and saturated it with ammonia; an abundant white flaky precipitate was formed, presenting the characters of phosphate of lime. To assure myself that the acid of asparagus was phosphoric acid, I treated with the blowpipe some grains of its combination with lead. It presented at first the same phænomena as the calcareous salt; it passed immediately to yellow, entered into fusion, and the button, on cooling, assumed the form of an irregular polyherton, a property exclusively belonging 
to the phosphate of lead. It is thus demonstrated, that if this acid had presented, in its principle, differences from phosphoric acid, it must have happened from its holding in solution an animal matter, and which $I$ believe to be the same with lwat which this matter contains in the green fecuience: at least, I dissolved a portion of the latter in pure phosrinoric aciri, I evaporated it so as to burn the animal sunstance, and there was developed an odour very similar to that which the phosphoric acid of asparagus yields.

In was in tiat portion of the extract that was insoluble in alcchol that I ougit to have found, accorking to M. Antoine, this arsal matter, which he has recognised for gelatine. Disticed water, as I have shown, entirely redissolved this extractive substance; and although it had been washed repeatedly with alcohol and dissolved in water, it reddened. very sensibly turnsole paper.

I believed it possible that the precipitate formed by infusion of galls was occasioned by an animal substance held in solution by means of this free acid; consequently I pourcd into the liquor ammonia till it was saturated. There was a very abundant flaky precipitate, which I separated by the filter and washed very carefully. The solution, united with the washings, did not give any more precipitate with gallnut; and the acetate of lead, as well as the oxygenated muriatic acid, did not produce any change.

I burnt a part of the precipitate formed by ammonia to have some notion of its nature; but in place of presenting the characters of an animal or vegeto-animal matter, as I suspected it to be, it burnt without swelliug, and left for residue a grayish powder, which I ascertained to be a calcareous salt. This experiment showed me, that if the liquor had ceased to precipitate by gall-nut, \&x. this would have depended mercly on the degree of concentration. I therefore evaporated it; and after having reduced it to threefourths of its volume, I still obtained precipitates by the acetate of lead, the oxygenated muriatic acid, and gall-nut.

I continued the evaporation till $I$ obtained a dry extract : it was of a dark brown colour, had an agreeable taste, a little saltish, and slightly attracted the humidity of the at- 
mosphere. I calcined a part of it; it swelled considerably, and the smell that was disengaged rather announced a vegetable substance than a product of an animal nature. The incinerated charcoal left a little lime. Thus certain reagents denoted the presence of an animal matter; others appeared to show the opposite. To obtain a more conclusive result, I redissolved this extract. I treated it with tincture of galls, and after washing and drying the precipitate, I submitted if to distillation to see if it yielded ammonia. Some was disengaged, but very small in quantity; so that, although we cannot deny that this principle, which is soluble in water, has many characters exclusively belonging to animal matters; it is, however, fair to say, that it has some properties which appear very different, and which could not agree with the admission of animal gelatine.

It only remains to me to speak of a salt which is found in the decoction and in the juice of asparagus. To obtain it, we ought to evaporate both to the consistence of thick syrups. At the evd of some days a salt is deposited, which when washed and redissolved in water, presents the following properties : it crystallizes in little rhomboids more or less regular, transparent and very white, almost insipid; very little soluble in the cold, but much more so in heat; and depositing itself upon cooling : it swells when burning; giving out a sharp but agreeable smell, and a little ammoniacal. Its charcoal, which was very considerable in volume, is easily incinerated, and leaves very little residue: when pounded with caustic alkali it gives sensible marks of ammonia. Its solution is not precipitable either by the alkalis or by alkaline earths. The oxalate of ammonia produces a slight turbidness, the muriate of barytes and the nitrate of silver do not occasion any change, neither is it decomposed by acetate of lead. Thus all that I have been able bitherto to discover of its nature is, that it has a double base, lime and ammonia; but I must confess I am entirely ignorant what acid is its constituent. Its not decomposing the acetate of lead and the muriate of barytes; prevents us from confounding it with tartarous acid, oxalic acid, \&c. Vinegar is what appears to come nearest to it; but it is in 
vain that I have tried to produce a similar salt with the acetous acid. I am therefore obliged to wait till I shall have obtained a greater quantity of the salt which this juice contains, before I can pronounce definitively on the nature of this acid.

I must further observe, that the presence of ammonia does not authorise us to think that we cannot obtain this triple salt till after having allowed a commencement of alteration in the juice of asparagus; for I have had it on evaporating decuctions and juices recently prepared, but always in smail quantities,

To recapitulate what I have had the honour of laying before you, I shall detail the principal substances which have been furnished me by the juice of asparagus. The green feculent substance is itself composed of three others; the first insoluble in alcohol, and which approaches nearer to the nature of animal matter than any that is contained in the vegetable. The two others are soluble; but one of them is deposited on cooling. This is what I call vegetable wax. The latter is only obtained by evaporation, and appears to hold a middle nature between volatile oils and resins.

We find in the filtered juice, 1st, Albumen, which coagulates on the first ebullition: 2d, Phosphate of potash, of which we separate the acid in precipitating it by the acetate of lead: 3d, The same acid combined with lime, and held in solution by a portion of free acetous acid : 4th, Foliated earth (de la terre foliee) and phosphate of potash in very great abundance: 5 th, The vegeto-animal substance which is found in the aqueous solution: $6 \mathrm{th}$, An extractive matter which we obtain after having precipitated by gall-nuts that portion of the extract which is insoluble in alcohol: 7 th, $\mathbf{A}$ triple salt of lime and ammonia, of which the acid is yet unknown to me: 8 th, and lastly, A colouring principle susceptible of becoming red by acids and yellow by alkalis*.

The results which I have obtained are different, as you observe, in several points from those announced by M. Antoine; but I beg you to remark that we have not followed

* It may be presumed that it is the acetous acid which carries the animal substance of the green feculum with it down to the urinary passage 
the same mode of analysis, and that certain substances which I have separated without difficulty, could not present themselves to him but after a number of experiments. But I am f.r from pretending to have made a complete analysis, and I shall esteem myself very fortunate if $I$ have been able to present you with some facts worthy of your attention.

XXIV. On the inverted Action of the allurnons Vessets of Trees. By Thomas Andkew Knight, Esq. F.R.S. In a Letter to the Right Honourable Sir Joseph Banks, K.B.P.R.S.*

I MY DEAR SIR,

1 HAVE endeavoured to prove, in several memoirst which you have done me the honour to lay before the Royal Society, that the fuid by which the various parts (that are annually added to trees, and herbacenus plants whose organization is siailar to that of trees, ) are gentrated, has previcusly circulated through their leaves $\ddagger$ either in the same or preceding season, and subsequently descended throngh their bark; and after having repeated every experiment hat occurred to me, from which I suspected an unfavourable result, I am not in possession of a single fact which is not perfectly consistent with the theory I have advanced.

There is, however, one circumstance stated by Hales and $\mathrm{Du}$ Hamel which appears strongly to militate against my hypothesis; and as that circumstance probably induced Hales to deny altogether the existence of circulation in plants, and Du Hamel to speak less decisively in favour of it than he possibly might otherwise bave done, I am anxious to recon-

* From Philosophical Transartione for 1805.

+ In the Phil. Trans. for $18.71,180$, 1804, and 1805.

$\$$ During the circulation of the sap through the leaves, a tramaparcnt fluid is emitted, in the night, from pores situated on their edges; and, on evaporating this liquid, obtained from very luxuriant plants of the vine, I found a very large residuun to remain, which was similar in external appearance to carbonate of lime. It must, however, have been evidently a very differer.t substance, from the rery large portion which the water held in solution. I do not know that this subsiance has been aualysed, or noticed by any naturalist.

cile 